and showed a positive attitude toward participation to learn GIS. However, whether they actually participate is questionable since there is a strong tendency that many often do not act in accordance with their answers in questionnaire. In order to break this tendency, the acquisition of the GIS skill could be made as a requirement in the teacher-training course and teacher's development program. Further, the acceptance system of universities for their teacher training and institutes for their teacher's development to teach GIS is insufficient. Therefore, a concrete class model and training curriculum for the acquisition of GIS skill should be immediately discussed and the environment which is necessary for learning the GIS skill in universities and institutes should be provided.

\section{Some Comments on Supporting the Educa- tional Use of GIS}

SAITO Tadamitsu Japan Map Center

In order to understand the community where students live as well as international society, the effect of GIS (Geographic Information System) at school are needed. This paper reports the present conditions of map data, which is one of the important topics in GIS utilization. Sales volume of paper maps such as 1:25,000 scale maps, which have been traditionally used in social studies classes, has dramatically dropped from 8.5 million sheets in its peak period to 2.1 million as of 2003. On the other hand, map data sold more than 22,000 copies last year. As this example shows, the sales method is transformed from paper maps to the form of CD-ROM and car navigation or via the Internet. If paper maps are no longer used, maps should be used with GIS software. At the web page of Japan Maps Center, 19 kinds of free GIS software are introduced and over 100 kinds of GIS software are listed. In the Educational GIS Forum, a report titled "Study on the GIS Utilization" was made, the first nationwide survey of GIS utilization. In the classes of local study, geography and synthetic study GIS helps students understand their community, geographic features and so on. In such classes, paper maps, map data and GIS should be used in a balanced manner. Japan Map Center is supporting the dissemination of maps and GIS by annually holding "Map Educational Research Seminar" and "GIS Utilization Seminar" and by assisting "GIS System Exhibitions" across the country. At the last symposium, the importance of taking the idea of the teachers was recognized. In order to disseminate GIS in school education, our support should be continuously extended so that such symposiums are held at various places in Japan.

\title{
The Globalization of Japanese Tourism
}

\section{Introduction}

This symposium examined the changes that occur in tourist destinations in Japan and abroad through the influence of increasing numbers of Japanese overseas travelers and incoming foreign tourists. Two papers focused on the outbound market and two on inbound tourism in Japan.

\section{Japanese Tourists in the Alpine Countries}

KUREHA Masaaki

University of Tsukuba

The purpose of this study is to examine cha- racteristics of Japanese tourism in the Alpine Countries. The number of Japanese travelers abroad has been increasing since 1964. More than 15 million Japanese travel abroad every year, recently. Although Europe is not dominant as the main destination area of Japanese, we can investigate their travel activities in detail with better-developed statistics there. The author analyzes the form of Japanese tourism in Switzerland and Austria focusing on the regional destinations and use of lodging facilities, compared with tourists from other countries.

Japanese tourists tend to visit some limited 
places in Switzerland. Most Japanese stayed nights in Zermatt, a village at the foot of the Matterhorn, with 16\% (0.15 million nights) of total Japanese tourist nights in this country in 2000. It was followed by Interlaken (15\%), Geneva (12\%) and Grindelwald (11\%). Compared with this trend, total tourists in Switzerland (mainly European) do not indicate such concentration of staying places in mountainous region. In terms of using accommodation, most Japanese stay at Hotels that are known as most expensive lodging facilities in Switzerland. The length of stay at a tourist place is much shorter than other tourists. In Austria, Japanese tourists have the same feature as in Switzerland. The concentration of their limited destination is more essential in Austria and can be seen in urban areas. 62\% (0.3 million nights) of total tourist nights are spent in Vienna and 14\% in Salzburg in 2002. Further, most Japanese visitors stay at Hotels among the highest class only for two or three days. As a result, Japanese tourists in the Alpine Countries tend to stay at some particular tourist areas for shorter period. Furthermore, the average amount of their consumption used to be much more than many tourists from other countries, using expensive facilities. These facts are mainly based on the general character of Japanese travel activity. Their destination places have recognized the Japanese traveler as one of the important segment of visitors. Especially, Japanese tourists have become indispensable for mountain resorts in Berner Oberland in Switzerland, such as Interlaken and Grindelwald, where Japanese tourists have formed the main visitor market and changes in the traditional landscape have also been observed.

\section{Japanese Tourists towards Australia}

ASAMIZU Munehiko

Ritsumeikan Asia Pacific University

Tourism is one of the largest industries in Australia nowadays. According to the ABS (Australian Bureau of Statistics), tourism GDP was approximately 32 billion Australian dollars and it shared $4.2 \%$ of Australia's GDP in 20022003 financial years. Tourism is also important for the work force and created 540 thousand employees in the same financial years. Over- seas visitors spent 16.6 billion Australian dollars, which was $11.2 \%$ of total exports in those financial years.

Inbound tourism is larger than export of iron or coal for the present. However, the inbound tourism market in Australia in the 1960s was rather small and Australia was an outbound country like the current Japanese situation. Because of Australia's rich natural resources mostly exported to Japan, a lot of Australian people had enough income and leisure time for their outbound travel until the Oil Shock in 1973.

At present, Japanese are one of the largest inbound tourist groups for Australia and approximately 700 thousand visitors arrived at Australia in year 2000. Historically, Japan has had a strong influence on the Australian economy, including the tourism industry. During the bubble economy of the late 1980s, Japanese tourism developers with strong yen rushed into Australia for huge resort developments or real estate investments mainly for Japanese customers. In addition, Australia's ethnic free multicultural policy since the 1970 s contributes to welcome Asian visitors especially from Japan legally and psychologically. Rapid increase of Japanese visitors also stimulated Australia's Japanese studies focus on young Australian residents' job hunting.

However, the end of the bubble economy in the early 1990s changed Australia's tourism dramatically. Instead of Japanese huge developments, Australia is seeking sustainable tourism which is environmentally friendly, contributes to the local community and needs less money for new development. Sustainable development is becoming popular world wide since the earth summit held in 1992, however, Japan's economic slump rapidly accelerated Australia's tourism towards nature based direction. In addition, as Aboriginal people in Australia have a traditionally environmentally friendly way of life, Australia could create very unique sustainable tourism. The uniqueness of tourism is attractive for inbound visitors and the Australian federal government also introduced nature based Aboriginal culture into the Sydney Olympic Games which is the so called 'Green Olympic' held in year 2000. 


\section{Formation of Highland Resorts with the Diffusion of Summering in the Meiji Era}

SATO Daisuke and SAITO Isao

University of Tsukuba

For the purpose of a summer refuge from the heat and disease of the tropics, hill stations were developed by English rulers in colonial India. This idea was carried by western colonists to Southeast Asia. We have already published certain studies that clarified the development process of highland resorts in Japan. These studies used cadasters, foreigners' diaries, and directories as well as newspapers. Collating these case studies, we would like to clarify the formation process of highland resorts with the diffusion of summering from Yokohama and Tokyo during the Meiji era.

Initially, Miyanoshita and Nikko developed into resorts due to the foreign adventurers from Yokohama in the late 1860s. These adventurers would reside in hot spring lodges or historical temples, where they could experience traditional Japanese culture. However, these places became unsuitable for long summer vacations since they were transformed into bustling townships by the numerous tourists who made short visits, including package tourists from Western Europe. Moreover, at 700 meters elevation, the weather in these places was not very cool.

Foreigners belonging to the upper class, such as diplomats and representatives of large companies, developed satellite resorts along Lake Ashinoko near Miyanoshita in the mid-1870s and along Lake Chuzenji near Nikko in the late 1880 s. They could have a comfortable stay in these resorts because the two resorts had a quiet and cool atmosphere, which is characteristic to remote places and high altitudes.

Since the bases of the Christianity missions were built under foreign concessions, from the late $1880 \mathrm{~s}$, missionaries started spending the summer in Karuizawa. A majority of the missionaries hailed from North America. In other words, people who came from North America followed the example of the Englishmen, who summered in the highlands. A highland resort, termed an America-mura (meaning American village), was also developed at Gotenba in around 1900 by Americans residing at Yoko- hama.

From what has been mentioned above, it follows that the first highland resorts were developed at Miyanoshita and Nikko in the late 1860 s, primarily by Englishmen, for the purpose of recreation and to satiate their curiosity regarding Japanese culture, while the satellite resorts along the lakes were formed from the mid- 1870 $s$ onward. With the increase in the number of missionaries and the expansion of trade with the U.S. during the late 1880 s, American resorts such as Karuizawa and Gotenba were developed in the remote areas.

\section{Characteristics of the Foreign Tourists in Tourist Resorts in Kyushu}

IKENAGA Masahito

Nagasaki International University

The purpose of this research clarifies the promotion and subject of the Nagasaki pilgrimage tour as characteristic of foreign travelers in Kyushu, a measure of the increase of foreign tourists, and sightseeing promotion. The result is as follows.

The number of traveling foreigner who visited Kyushu in 2002 occupied $8.4 \%$ of the whole country (440,000 people), among those South Koreans were 57\% (250,000 people). Moreover, $20 \%$ of the South Korean travelers who visited Japan traveled to Kyushu. South Korean travelers in the tourist resort in Kyushu was the main group tour. Furthermore, their travel purposes were hot spring bathing, golf, pilgrimage, etc. In addition, foreign travelers other than South Koreans were people from Taiwan, China, Hong Kong, and America.

The Kyushu area strategy meeting decided upon the Kyushu sightseeing strategy plan in September, 2004 in order to increase foreign tourists. This plan is to be carried out from April, 2005. The main contents are creation of sightseeing guidance signs in four languages of Japanese, English, Chinese, and Korean, installation of a telephone center, formation of the East Asia sightseeing guidance organization, exhibition of an overseas sightseeing trade fair, establishment of the Kyushu inheritance, and promotion of industrial sightseeing.

For the Nagasaki pilgrimage tour, the Nagasaki Prefectural Tourist Federation will in- 
vite the persons involved in South Korean from 2001 , and is inspecting churches and historical relics in Nagasaki. The Nagasaki pilgrimage tour was completely carried out from 2003. The places of pilgrimage tour are Nagasaki city, the Shimabara peninsula, the Goto islands, and Hirado island. The number of tour participants aims at 2,000 people every year. The preparations for the pilgrimage ground of Nagasaki Prefecture are training of an interpreter guide, and creation of a multilingual pamphlet, explanation board, and guidance sign.

Thus, the following three advantages can be acquired by promoting a visit to Japan of incoming tourists. That is, improvement of international mutual understanding, local promotion by formation of confidence and pride of local residents, and development of the Japanese economy.

\section{The Adaption of Domestic Tourism Desti- nations to International Tourism}

FUNCK Carolin

Hiroshima University

This paper introduced the current campaign by the Japanese government to increase the number of foreign tourists, called "Visit Japan Campaign" (VJC). The background for this campaign is the gap between the large number of Japanese traveling abroad and the number of foreign tourists visiting Japan. Over the last 40 years, both numbers have been growing, and this has influenced tourist destinations in Japan in many ways. At present, most foreign tourists visiting Japan arrive from Asia, especially South Korea, Taiwan, Hongkong and recently China. Those traveling in groups visit typical destinations of Japanese mass tourism like famous hot spring resorts and theme parks. As Japanese tourist destinations have to compete directly with destinations abroad for Japanese tourists, it is only naturally that they try to attract foreign tourists to make up for the decrease of domestic tourists.

The paper looked at Miyajima Island in $\mathrm{Hi}$ roshima prefecture as an example of how destinations adapt to foreign tourists. Hiroshima prefecture is somewhat special in that it attracts mainly tourists from North America and Europe who come to visit the sites connected to the atomic bomb, often combined with a trip to Miyajima Island.

To analyze the perspectives of Miyajima as an international tourist destination, a variety of approaches like questionnaires, monitor tours and SWOT analysis were used. As a summary of the opinion of foreign visitors it can be said that while Miyajima has a large variety of attractive tourist resources, a lack of foreign language capability, high prices and the lack of an overall concept for tourism development on the island were seen as inhibiting factors. On the other hand, residents and shop owners tend to rely on having information in foreign languages provided in form of maps and signs or through volunteer guides, whereas owners of accommodation facilities showed a more active interest in promoting Miyajima as an international tourist destination. Recently, inns and shops renovated in traditional or modern Japanese style have added variety to the tourism facilities of Miyajima and prove to be popular with foreign tourists.

\section{Discussion}

The discussion showed that tourism geography in Japan still lacks a common terminology that is compatible with English terminology of the same subject. The problem of accurate data was also touched upon. To discuss Japanese tourism in a global framework, basic research on data and terminology will be necessary. 